\title{
Article
}

\section{The relationship between stereotypical meaning and contextual meaning of Korean honorifics}

Chen, $\mathrm{Xi}$ and Lee, Jungmin

Available at http://clok.uclan.ac.uk/35393/

Chen, Xi ORCID: 0000-0003-2393-532X and Lee, Jungmin (2020) The relationship between stereotypical meaning and contextual meaning of Korean honorifics. Journal of Pragmatics, 171 . pp. 118-130. ISSN 0378-2166

It is advisable to refer to the publisher's version if you intend to cite from the work. http://dx.doi.org/10.1016/j.pragma.2020.10.011

For more information about UCLan's research in this area go to http://www.uclan.ac.uk/researchgroups/ and search for <name of research Group>.

For information about Research generally at UCLan please go to http://www.uclan.ac.uk/research/

All outputs in CLoK are protected by Intellectual Property Rights law, including Copyright law. Copyright, IPR and Moral Rights for the works on this site are retained by the individual authors and/or other copyright owners. Terms and conditions for use of this material are defined in the policies page.

\section{CLoK}

Central Lancashire online Knowledge www.clok.uclan.ac.uk

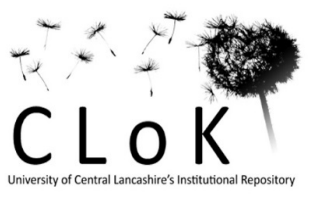




\title{
The relationship between stereotypical meaning and contextual meaning of Korean honorifics
}

\begin{abstract}
In this paper, we investigate the specific way that people's knowledge of an honorific's stereotypical meaning contributes to their understanding of its contextual meaning. Stereotypical meanings refer to language users' conventional belief about how an honorific should be used, while contextual meanings are the meanings created by their active choice of using an honorific in a context. We examine the relationships between the two through the special lens of Kim Jong Un's use of Korean honorific first-person pronoun ce in a North-South Korea summit. Drawn on thirty metapragmatic interviews with Korean native speakers, we find that contextual meanings of ce are metapragmatically related to different subsets of stereotypical meanings. The varied relationships between the two meanings follow the mechanism that people make cognitive relevance between their language choice and pragmatic interpretations. Participants' contextual awareness and language ideologies mediate the functionality of the mechanism, and hence explaining how and why one stereotypical meaning instead of another was activated in creating a contextual meaning. The nexus we found between metapragmatics, language ideologies, pragmatic effects and context potentially benefits multiple areas of research such as politeness, ethnolinguistics and second language acquisition.
\end{abstract}

Key words: Korean; pronoun; normative use; strategic use; language ideology

\section{Introduction}

In the end of April 2018, the summit between North and South Korea appeared in the headlines of major media outlets around the world. At its press conference, the North Korean leader, Kim Jong Un, made his speech using the honorific first-person pronoun ce in Korean, alternating with its non-honorific form na. While both ce and na were indifferently translated into ' $l$ ' in English, the subtle difference underlying this pronominal choice was immediately noted by the Korean-speaking media. Kim Jong Un's use of honorific ce was soon interpreted in a South Korean news report as conveying a meaning of politeness (yeyuy and conkyeng) and image change (casin-kwa kwanlyentoyn kocengkwannyem pakku-ki), as signifying his political intent (palcen-uy uyci) and as appealing to public sympathy (yelon) (Kim, Kyoungho, 
n.d. "'cenun' instead of 'nanun', 2018). The news report received a great deal of positive attention from South Korean netizens, including over 2,300 instances of positive emoticonic feedback (i.e. smile, thumb up).

However, the much-acclaimed meanings assigned by the press appear to differ greatly from the normative understanding of $c e$ in the Korean language. According to Korean language reference books (e.g. Chang, 1996; Yeon and Brown, 2011), ce is used to lower oneself in relation to a senior or non-acquaintance, in contrast to its non-honorific counterpart na, which is used with intimates, in equal relationships, or to juniors. These widely accepted prescriptive definitions represent, at least partially, "legitimation and replication" of stereotypes that Korean language users hold for honorific use (Agha, 2004:28). They are defined as 'stereotypical meanings' of an honorific (Okamoto, 2011), reflecting 'default interpretations' by language users (Pizziconi, 2011).

On the other hand, there are contextual meanings or situated meanings (Brown, 2015; Cook, 2011; Okamoto, 2011), such as 'appealing to public sympathy', 'image change' and 'political intent' as reported to be communicated via Kim Jong Un's use of ce in the summit. They are created by the speaker's actual use of $c e$ in this specific context. Ostensibly, stereotypical meanings of $c e$ do not provide any explanations for the variety of contextual meanings being created, just as many criticize the textbook definitions for its inability to account for actual honorific use. However, from South Korean netizens' reactions, we can see that the contextual meanings of ce, although distinct from its stereotypical meanings, are recognized, communicated, and even lauded in the South Korean speech community.

The question is then: how does the Korean speakers' knowledge of an honorific's stereotypical meanings contribute to their understanding of its contextual meanings? This study sets out to answer this question by exploring the relationship between the stereotypical meanings and contextual meanings of ce through Kim Jong Un's use of this honorific pronoun in his summit speech. It focuses on the specific ways that the two types of meanings are related and, more importantly, the mechanism underlying their connections. Through an analysis of Korean language users' "metapragmatic discourse" (Silverstein, 1993:35) which explicitly denotes the meaning connection, this study sheds light on the uncharted area of nexus between metapragmatics, language ideologies and pragmatics in Korean honorifics.

In the next section, we begin by introducing the background information about Kim Jong Un's speech and the news report of his pronominal choice. We then revisit theoretical and empirical studies of stereotypical meaning and contextual meaning in Section 3. In Section 4, we specify the interview data we used as metapragmatic discourse and organize the data by the meaning type. Using group query analysis, we find in Section 5 that different contextual meanings of $c e$ 
are related to different stereotypical meanings. The diversity of their relationships is further discussed in Section 6. In Section 7, we conclude with brief remarks of the findings and their meanings in second language acquisition.

\section{Kim Jong Un's speech for the Panmunjom Declaration and the public reaction}

The Panmumjom Declaration, officially titled the 'Panmunjom Declaration for Peace, Prosperity and Reunification of the Korean Peninsula', was presented at the inter-Korea summit on April 27, 2018. The declaration sought for 1) an end of the sixty-year long cold war and confrontation between North and South Korea; 2) co-prosperity and independent reunification; and 3) cultivation of inter-Korea relations (Ministry of Foreign Affairs, Republic of Korea, 2018). The importance of the summit has been highlighted by the Ministry of Foreign Affairs in South Korea as "the significant period of historic turn being made on the Korean peninsula".

Kim Jong Un made his speech to the press conference after co-signing the Panmumjom Declaration with South Korean President, Moon Jae In. His speech was 550 characters long in Korean, in which three pronouns were employed 11 times in the position of sentence subjects. These include three cases of using the honorific first-person singular pronoun ce, three using its non-honorific form na and five cases of using the first-person plural pronoun wuli (lit: we). All three instances of ce occurred when Kim Jong Un himself and Moon Jae In co-occurred as the subject of the sentence (i.e. "President Moon Jae In and I"). In contrast, na was used to refer exclusively to himself in single-subject sentences.

Throughout Kim Jong Un's speech, the deferential speech style -supnita, indicating formal presentational stance (Brown 2015), was consistently employed and did not change with his alternation of pronouns. In contrast, Moon Jae In used only the non-honorific na with the same speech style -supnita. It is worth pointing out that there is nothing grammatically inaccurate or pragmatically negative in using either ce or na with the -supnita style in this context.

The next day's news report from MBC, a leading broadcaster in South Korea, highlighted Kim Jong Un's use of ce as “Kim Jong Un's humble way of speaking” (Kim, Kyoungho, n.d. "'cenun' instead of 'nanun'" 2018) ${ }^{1}$. This report was soon followed by over 1,800 comments on a South Korean web portal (i.e. Naver), along with the huge amount of emoticonic feedback mentioned at the start of this paper. Figure 1 below shows the gender and age of participants in the online comments after real identity authentication:

\footnotetext{
${ }^{1}$ nun as in cenun and nanun is a topic particle in Korean.
} 


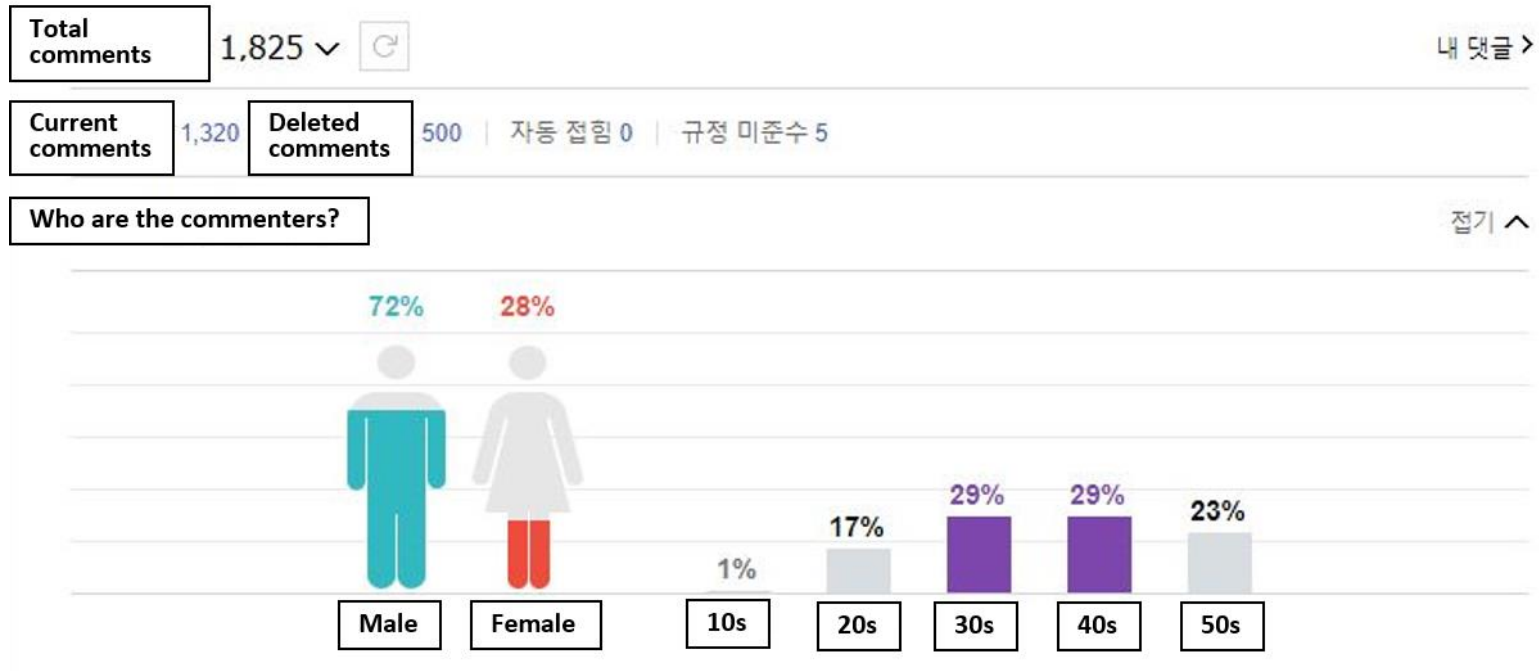

Figure 1. age and gender distribution in online comments

As shown in the above visualization, $72 \%$ of the comments were made by male netizens and $28 \%$ by females. Those in their 30 s, 40 s, and 50 s commented more than people in younger age groups. This distribution indicates uneven interest on the parts of different gender and age groups in the topic of Kim Jong Un's pronominal use. Variations between different gender and age groups that may be relevant for constructing the stereotypical and contextual meanings of honorific pronouns are accordingly taken into consideration in our data, which we will specify in Section 4.

\section{Stereotypical meaning and contextual meaning}

In this section, we revisit previous theoretical and empirical research of stereotypical and contextual meanings to understand the underlying constructions of these concepts. Also, given the topic of the current research, we exemplify the understanding of these two meanings in previous studies of honorifics and pronouns.

Stereotypical meaning is defined as a typical belief about how an honorific should be used in relation to certain types of contexts (Okamoto 2011: 3675). Comparing to similar notions such as 'normative use' (Brown, 2010; Lee, 1999) and 'default interpretation' (Pizziconi 2011), Okamoto's term well reflects its psychological nature as being language stereotypes recurrently typified in a speech community (Agha, 2004). Members of the speech community learn the stereotypes socially (Mackie et al., 1996). For example, native speakers of Korean learnt and may still be learning from their parents to use honorifics to elders. These kinds of socially learnt stereotypes usually conform to existing social norms (Thibaut and Kelley, 1959) 
and are hence justified by people's language ideologies. For example, ce is enacted to address asymmetrical power (i.e. with seniors) and a distant relationship (i.e. with nonacquaintance).

Language ideologies, or linguistic ideologies, are defined as "any sets of beliefs about language articulated by the users as a rationalization or justification of perceived language structure and use" (Silverstein, 1979:193). We use plural form for 'ideology' because its manifestations are always multiple (Kroskrity, 2010:197; Silverstein, 1979:214). They grow from and are encapsulated in people's metapragmatic accounts for language use (Silverstein, 1979, 2003; Verschueren, 2000). In actual communication, language ideologies are constantly negotiated, contested and even exploited with individual investments into creating contextual meanings. For example, while acknowledging honorifics are stereotypically expected from younger interlocutors, some western learners of the Korean language negotiate their ideology of equality by suggesting a symmetrical use of honorifics or non-honorifics regardless of age difference (Brown, 2008; 2010).

Contextual meaning is thus created by a speaker's active choice of using an honorific in a specific context. It is also regarded as 'strategic use' (Brown, 2010; Lee, 1999), 'social and pragmatic meaning' (Okamoto 2011) or 'situated meaning' (Brown, 2015; Cook, 2011). In the current study, we adopt only situated meaning interchangeably with contextual meaning. Both terms highlight the characteristic of the meaning being context-specific and are accepted relatively unanimously. The other terms have been variably defined in different studies, for example, 'strategic use' in Brown (2010) and in Morford (1997), 'social meaning' in Cook (2011), and in Simpson (1997). The variability in their definitions is beyond the current discussion.

Contextual meanings are often distinct from stereotypical meanings, because the latter experienced 'information loss' as it underwent the process of stereotyping. In other words, a meaning becomes stereotypical at the cost of neglecting the variability and specificity of different contexts (Mackie et al., 1996). Contextual meanings, on the other hand, are enriched by the re-engagement of variable and specific contexts in which honorifics are used. Pizziconi (2011) regards contextual enrichment as a constraint restricting people's meaning interpretations to the only one possible in a specific context. For example, an honorific, stereotypically perceived as used by a junior to a senior, must be interpreted otherwise after witnessing the real context of a teacher using it to a junior student.

The communication of contextual meanings is filtered by individuals' consideration of context and manipulation of language ideologies (Okamoto, 1997). In pronominal studies, for example, female students at a Thai university adopt a pronoun, the gender-bound ideology of which 
stigmatizes females, to create a meaning of equality in their relationship with friends (Simpson, 1997). Similar exploitation of gendered language ideologies can be found in Ogawa and Shibamoto-Smith (1997) and Miyazaki (2004). The latter finds a group of resistant and powerful Japanese schoolgirls uses the ideologically most 'masculine' pronoun ore as another group of athletic boys does, which formulates a peer-group specific relationship. In the political context, pronouns as rhetorical projection of one's identity and political ideologies have been extensively analyzed by previous studies (e.g. Kuo, 2002; Maitland and Wilson, 1987; Proctor and Su, 2011; Zheni, 2020), while only a few of them paid attention to their relationships with language ideologies (e.g. Fetzer and Bull, 2008; Kim, 2018; Morford, 1997). Morford (1997), among the few, reveals that French politicians from the upper class require their children to address them in public using $t u$ instead of vous, because tu encodes an egalitarian ideology through which politicians intend to better represent their voters from the lower-middle-class. In Korean, a recent study Kim (2018) provides useful insights into South Korean President Moon Jae In's pronominal choice. It argues Moon uses the honorific 'l' (i.e. ce) to index his humility and loyalty to people in his country by lowering oneself as a president (casin-uy wisang-ul nac-cu-e, 2008:12). Here, Kim (2018) demonstrates an intuitive account for the relationship between a stereotypical meaning (i.e. lowering oneself) and contextual meanings (i.e. humility and loyalty).

We should emphasize, however, that not all available ideologies are involved in creating a contextual meaning. As Silverstein argues, 'the second order indexical meaning' is "effective via different ideological position" at the metapragmatic level (2003:204). He uses "pragmatic presupposition' and 'contextual entailment' to distinguish the 'indexical orders' of an honorific. That is, the first order of indexical meaning presupposes what is appropriate for an honorific to be used normatively, while the second order is entailed by a context in which a meaning is created for effectiveness. The appropriateness and effectiveness reflect the metapragmatic parameters by which stereotypical meaning and contextual meaning are extracted. The appropriateness and effectiveness (as well as presupposition and entailment) are argued to have a cause-and-effect relationship (2003:203).

The cause-and-effect relationship is previously touched upon in a very general way by a limited number of honorifics studies. For example, in discussion of 'mock politeness', researchers find that the meaning of impoliteness is inferred on the grounds of the positive values that honorifics are typically associated with, such as respect (Culpeper et al, 2003:1555; Brown 2013:181). Similarly, rudeness can be inferred when honorifics are not stereotypically anticipated with a friend (Okamoto, 2011). In Korean, Brown believes that the "normative and ideological way" that language users understand an honorific should relate "in some way" to its situated meanings (2015:48). The key questions that have not been addressed in the 
foregoing studies thus pertain to the specific way stereotypical meaning and contextual meaning are related and why. This study addresses both of these essential questions in the following sections through the lens of Kim Jong Un's use of the Korean honorific pronoun ce.

\section{Data}

In order to access stereotypical and contextual meanings understood by language users, we recruited 30 Korean native speakers from different age and gender groups for one-to-one interviews. The interviews formulated metapragmatic discourse (Silverstein, 1993:35) which enabled us to explicitly identify the relationship of the meanings. Section 4.1 below presents the data collection and 4.2 organizes the data by different types of meanings.

\subsection{Data collection}

\subsubsection{Participants}

In total, 30 interviewees were recruited in the greater Seoul area, South Korea, primarily through local volunteer groups and government approved organizations that promote civil society. There were ten participants in each of the three age groups: 30 to 39 years, 40 to 49 years and 50 to 59 years. This is in accordance with the age ranges who showed the most interest in this topic in the online comments.

Within each age group, there were five female and five male participants. In total, we had 15 participants of each gender. The even number of different genders is to balance possible gender influence on the one hand, and to explore gender-biased meaning interpretations in future on the other. All participants except one 50-year-old female had a university education. The participants' identities are kept confidential. Their quotations in this paper are identified by their age, gender, and order of interview, for example, 30s_female_01.

The second author acted as the interviewer. She is also a South Korean native and currently teaching Korean language in a British university. The interviews happened as a part of her fieldwork in Seoul, South Korea.

\subsubsection{The Interview}

All interviews took place on a one-to-one face-to-face basis in a location where both the interviewer and interviewee felt comfortable. Each interview was 15 to 20 minutes long, conducted in the Korean language, and audio recorded. The Korean interview records were 
transcribed and translated into English by a qualified translator. The accuracy of the transcription and translation was crosschecked by the researchers.

The greater part of the interview consisted of participants' answers to three general questions: (1) what do you think ce is normally used for; (2) what do you think about Kim Jong Un's use of ce in his speech; (3) why do you think that? The first question investigates interviewees' perceptions of stereotypical meanings while the second question asks about the contextual meanings of $c e$. The third question requires interviewees to elaborate on the reasons for their interpretations of the contextual meanings.

The three general questions were also extended to specific questions following the conversational flow in each interview. The interviewer did not make any judgements or pose any leading questions, but at times prompted interviewees using the exact same or similar words as they had used. For example, if an interviewee mentioned that ce was used strategically by Kim Jong Un, then the interviewer could further the questions "what makes you feel this is a strategic use?" or "what do you think this strategic use is for?"

\subsection{Data analysis}

Data collected from the 30 interviews was analyzed using NVivo. The first level of analysis was to identify the stereotypical meanings and contextual meanings which account for interviewees' perceptions, as well as the reasons for their interpretations of the meanings. Considering the variability of individuals' perceptions, we adopted a bottom-up approach to extract the stereotypical meanings, contextual meanings, and reasons in terms of frequency. Tables 1, 3, and 5 below list different stereotypical meanings, contextual meanings and reasons with examples. Frequencies of each type can be found in Tables 2, 4, and 6.

\subsubsection{Stereotypical meanings of ce}

As we discussed in Section 3, stereotypical meaning is a typified belief formulated through a process of social learning, and hence has a degree of consensus between members of a speech community. In other words, the stereotypical meanings perceived by one person may also be possessed by other members of the group. Table 1 below displays the stereotypical meanings frequently identified by our interviewees and Table 2 computes their frequencies, i.e. the number of occurrences that each meaning was explicitly mentioned by the interviewees. 
Stereotypical meaning of $c e$

\begin{tabular}{|c|c|}
\hline Stereotypical meanings & Examples from interview data \\
\hline elevating others & $\begin{array}{l}\text { Sangtaypang-ul nophi-nun uymi-ka iss-ul kes kath-ta. } \\
\text { 'It seems to have the meaning of elevating the other party.' } \\
\text { (40_female_05) }\end{array}$ \\
\hline lowering oneself & $\begin{array}{l}\text { Sangtaypang-hanthey na-lul nac-cwul-ttay-na elun-hanthey } \\
\text { yaykihal-ttay ce-la-nun phyohyen-ul manhi ssun-ta. } \\
\text { 'When (I need to) lower myself to the other party or when talking } \\
\text { to elders, the expression ce is used a lot.' (40_male_01) }\end{array}$ \\
\hline (using to) group audience & $\begin{array}{l}\text { Taycung-tul ap-eyse sel-ttay kyeksik-ul kacchwe-ya ha-nun } \\
\text { cali-cengto toyl kes kath-ta. } \\
\text { 'It comes in front of a group audience with some } \\
\text { formality.'(40s_female_05) }\end{array}$ \\
\hline $\begin{array}{l}\text { (using } \\
\text { nonacquiantance }\end{array}$ & $\begin{array}{l}\text { Chinpwun-i eps-nun pwun, cheumpo-nun pwun-tul-eykey } \\
\text { sayonghan-ta. } \\
\text { '(It is) used to a non-acquaintance, someone (you) met for the } \\
\text { first time.' (50s_female_05) }\end{array}$ \\
\hline (using to) older people & $\begin{array}{l}\text { Casin-pota nai-ka manh-un salam-hanthey ce-la-nun } \\
\text { phyohyen-ul sayonghan-ta. } \\
\text { 'To someone who is older than myself, the expression ce is } \\
\text { used.'(40s_female_01) }\end{array}$ \\
\hline $\begin{array}{l}\text { (using to) people with } \\
\text { power }\end{array}$ & $\begin{array}{l}\text { Nai-ka manh-kena cikkup-i noph-un salam-eykey ssun-ta. } \\
\text { '(It is) used to someone who is older or higher in rank.' } \\
\text { (30s_male_02) }\end{array}$ \\
\hline
\end{tabular}

${ }^{*}$ For ease of presentation, the information in parenthesis above may be omitted in later sections. 'older people', 'people with power', 'nonacquaintance' and 'group audience' are used as shorthand of the corresponding stereotypical meanings.

Table 2

Frequencies of different stereotypical meanings

\begin{tabular}{|l|l|l|}
\hline Category & Frequency & Percentage (\%) \\
\hline elevating others & 15 & 12.93 \\
\hline lowering oneself & 24 & 20.69 \\
\hline group audience & 20 & 17.24 \\
\hline nonacquaintance & 14 & 12.07 \\
\hline older people & 22 & 18.97 \\
\hline people with power & 10 & 8.62 \\
\hline others & 11 & 9.48 \\
\hline Total & 116 & \\
\hline
\end{tabular}


The stereotypical meaning that Korean interviewees identified the most was 'lowering oneself', followed by 'older people' and 'group audience'. Surprisingly, the prescribed 'people with power' in textbook definitions appeared to be peripheral compared to other meanings.

The multiplicity of the stereotypical meanings in fact transcends the established ideologies that see ce as an index of power and distance. To be specific, using ce to people with power and nonacquaintance indicate that the relationship between interlocutors is asymmetrical in status and distant, with the addressee/referent hierarchically higher. The way of essentializing a pronoun's stereotypical meanings into addressees' social identity and relational equality has well been suggested by Silverstein (2003) in his discussion of first order indexicality of honorifics.

In addition to these essentializations, 'lowering oneself' and 'elevating others' indicate ce also acting as a two-sided linguistic realization of deference (Hwang, 1990). 'Older people' are ideologically regarded as socially higher in Korean, i.e. "people above me" (Yoon, 2004:201). However, metapragmatically Korean people categorize them separately from hierarchical superiors who have control over the speaker, namely 'people with power'. Unlike powerful superiors, age-superiors do not have the authority over younger interlocutors for verbal compliance and submission (Yoon, 2004:203). Using ce to older people is rather driven by the interlocutor's own desire for social reputation, for example, not suffering from judgment of pelus-i eps-ta (ill-bred). 'Group audience' was encoded in interviewees' expressions of taycung (the general public), yeles-i (many people) and tanchey (group). Speaking to a group audience was metapragmatically associated with highly structured scenes such as epmu (business), cikcang (workplace), moim (gathering) in which the speaker him/herself is tanchey-uy kusengwen (one group member). The behavioral expectation for presenting oneself in these standard situations (House, 1989, cf. House and Kádár, 2020) is to preserve a level of linguistic formality (kyeksik kacchwuta).

\subsubsection{Contextual meanings of ce}

As with the interpretation contained in the news report, contextual meanings were understood differently from the above stereotypical meanings. Below, Table 3 illustrates the types of contextual meanings with examples and Table 4 calculates their frequencies.

Table 3

Contextual meanings of Kim Jong Un's use of ce 


\begin{tabular}{|l|l|}
\hline Contextual meanings & Examples from interview data \\
\hline image management & $\begin{array}{l}\text { Pwukhan-i wihemhan concay-lo poi-eci-ciman ce-la-nun } \\
\text { phyohyen-ul ssum-ulose kulen image wanhwa-sikhi-nun } \\
\text { yekhal-ul ha-ci anh-na kulen nukkim-i tun-ta. }\end{array}$ \\
'North Korea is regarded as a threatening entity but using the \\
expression ce plays a role in mitigating that threatening image.' \\
(40s_male_01)
\end{tabular}

Table 4

Frequencies of different contextual meanings

\begin{tabular}{|l|l|l|}
\hline Category & Frequency & Percentage (\%) \\
\hline image management & 47 & 30.92 \\
\hline politeness & 38 & 25 \\
\hline building solidarity & 21 & 13.82 \\
\hline political intent & 15 & 9.87 \\
\hline consideration for others & 9 & 5.92 \\
\hline appeal to public sympathy & 9 & 5.92 \\
\hline others & 13 & 8.55 \\
\hline Total & 152 & \\
\hline
\end{tabular}


'Image management', 'politeness', and 'building solidarity' are the three contextual meanings that the interviewees assigned most frequently to Kim Jong Un's use of ce. They account for approximately $70 \%$ of the total contextual meanings.

It is not a surprise that using ce contextually changes one's image, given the nature of firstperson pronouns being indexical of an interlocutor's self-presentation. A similar argument can be found in Maitland and Wilson (1987) that British politicians changed their image through their use of ' $l$ ' and 'we'. In addition to pronominal choice, the alternation from non-honorifics (i.e. na) to honorifics (i.e. ce) also changes the social values laden with oneself (Agha, 1998:166), hence changing one's image.

Politeness being a contextual meaning, instead of stereotypical meaning, is supported by previous studies of Korean honorifics (Hwang, 1990; Lee, 1999). That is, politeness is created via a speaker's strategic choice of honorifics, rather than a property inherent in them. This finding corresponds nicely with the emic understanding of politeness, namely, whether an honorific is polite or not depends on interlocutors' contextual judgment ('politeness 1' in Eelen 2001).

Unlike the above two meanings, the finding that contextual meaning 'building solidarity' is indicated by the honorific ' $l$ ' in Korean appears to contrast with T/V studies in European languages (e.g. Brown and Gilman, 1960; Morford, 1997). The latter generally believes that it is the non-honorific tu building 'solidarity' through indicating an egalitarian ideology. This difference possibly stems from, firstly, the different indexicalities of first-person pronouns (i.e. ce/na) and second person pronouns (i.e. T/V). Secondly, Koreans and Westerners (whose languages have T/V pronouns) have different metapragmatic interpretations of solidarity. Our interviewees' metapragmatic commentary seems to corroborate the second reason, that nonhonorific na indicates Kim Jong Un is speaking in his empowered role by showing the equal and independent status of the speaker, while honorific ce takes the standing of others into consideration and thus is perceived as solidarity-building.

\subsubsection{Reasons for meaning interpretations}

While it does focus on the relationship between stereotypical meaning and contextual meaning, this study does not assume that stereotypical meaning alone determines the communication of contextual meaning. Neither is their relationship one of simple mapping. To explore how the interviewees envisaged their relationship, we further asked them to specify their reasons for their interpretations of contextual meanings. Table 5 presents the reasons with examples and Table 6 provides their frequencies. 
Table 5

Reasons

\begin{tabular}{|l|l|}
\hline Reasons & Examples from interview data \\
\hline age & $\begin{array}{l}\text { Kkok iyu-lul pwuthi-camyen nai-ka cekyongtoy-nun kes kath-ta. } \\
\text { 'If (I) have to find a reason, age may apply (here).' } \\
\text { (30s_female_05) }\end{array}$ \\
\hline strategic deliberation & $\begin{array}{l}\text { Kim Jong Un wiwencang-to na-wa ce-uy uymi-lul simsaswukko- } \\
\text { hayss-ul kes-i-ta. } \\
\text { 'Chairman Kim must have also carefully considered the } \\
\text { meanings of na and ce.'(40s_male_05) }\end{array}$ \\
\hline traditional Korean culture & $\begin{array}{l}\text { Hanmincok cengsanghoytam-i-lase yukyocek-in pathang-i tul- } \\
\text { ess-ul kes-i-ta. } \\
\text { 'As being the inter-Korea summit, Confucianism must have } \\
\text { acted somehow as a background.'(50s_female_01) }\end{array}$ \\
\hline position & $\begin{array}{l}\text { Ilehkey oykyocek-ulo seykyeyin-tul aph-eyse han kes-un thossi } \\
\text { hana-lato ta chayngkin-tako sayngkakhan-ta. } \\
\text { 'When being diplomatic in front of the whole world I think even } \\
\text { a single word needs to have attention paid to it.' } \\
\text { (40s_female_01) }\end{array}$ \\
\hline
\end{tabular}

Table 6

Frequencies of different reasons

\begin{tabular}{|l|l|l|}
\hline Category & Frequency & Percentage (\%) \\
\hline age & 45 & 39.13 \\
\hline strategic deliberation & 32 & 27.82 \\
\hline traditional Korean culture & 17 & 14.78 \\
\hline position & 12 & 10.43 \\
\hline others & 9 & 7.83 \\
\hline Total & 115 & \\
\hline
\end{tabular}

When explaining their interpretations, the interviewees found multiple extra-linguistic reasons. As listed above, age refers to the age difference between Kim Jong Un and Moon Jae In (the South Korean President) as well as the South Korean audience. Position is a translation from the Korean word cali, which refers to both social position and spatial position. The two concepts could hardly be discerned though, when interviewees referred the context as "such a call" without further specification. Possibly, they intended to include both in one word, too. Traditional Korean culture includes interviewees' explanations pertaining to the socio-cultural background, such as Confucianism, which they thought applicable to their meaning 
interpretation. Strategic deliberation reflects interviewees' inference of Kim Jong Un's intentionality. One piece of evidence interviewees used to support 'strategic deliberation' is that Kim Jong Un alternatively used ce and na in the same speech. In other words, whether to use one pronoun or the other appeared to be strategic.

Some of the reasons seemingly overlap with stereotypical meanings, for example, the reason 'age' overlapping with the stereotypical meaning '(using to) older people'. The overlap stems from the fact that stereotypical meanings conform to social norms, as specified in Section 3. In other words, Koreans' acquisition of the stereotypical meaning '(using to) older people' may conform to the social norms of treating 'age' (possibly 'age difference'). However, 'age' as a reason conveys a broader societal background such as the aging society of South Korea, which is irrelevant to ce being used to older people (see Section 5). Also, a public 'position' may sound related to '(using to) group audience', but they differ in terms of an individual's standing as being a group member or not (see Section 6).

In Tables 2, 4, and 6, there is a sub-category - 'others'. It collects coded answers to our questions about stereotypical meanings, contextual meanings, and reasons that were not classifiable in any other sub-category. The inclusion of the 'others' sub-category in this study allows us to acknowledge that there are also infrequently encountered meaning interpretations that reflect highly idiosyncratic understandings of ce. People's understanding of the meanings and reasons is constantly evolving in discursive communicative practice. Unclassifiable answers may reflect an unconventional evolution restricted to a very personal experience, which is beyond the current discussion.

All of the above coding was carried out by two raters working independently. The inter-rater reliability was tested using the Kappa statistic and the results showed high inter-rater agreements: .74 (stereotypical meaning), .87 (contextual meaning) and .90 (reasons). The two raters further discussed the discrepancies in their coding until $100 \%$ agreement was reached in each category.

\section{The relationship between stereotypical meaning, contextual meaning and interviewees' reasons}

The relationship between the stereotypical meanings and contextual meanings can be identified by interviewees' use of "metapragmatic framing devices" (Silverstein, 2003:196). The devices are grammaticalized or lexicalized indicators of metapragmatic awareness regarding the connections between stereotypical meanings and contextual meanings, which included causal connectives -ase (as, because), -nikka (because),-ki ttaymun (because, due 
to), -(u)mulo (as, by), instrumental particle '-(u)losse (as being), conditional connective lyemyen (if you want), and idiomatic lexemes waynyahamyen (if you ask why), kulayse (so) and others. An example can be found in Table 3 above with the causal connective -ase highlighted. In addition to the metapragmatic framing devices, the relationship is also recognized in discourse organization. For example,

Example (1):

30s_male_04: kulentey kukey [image] pakkwi-nuntey-ey ce-la-nun phyohyen-i han mokshayss-ulkka... ce-nun-i-la-nun kes-ul po-ass-ul ttay-nun com te cehuy-lul ollye-cwu-nun tushan nukkim-i manh-ass-ki ttaymun-i-ta.

'But can we say ce played a role in changing it [image]... Because, when looking at ce-nun, I feel we have been uplifted.'

In his answer, the interviewee first confirmed ce played a role in creating the meaning 'image change', using a word '(doing one's) moks' (lit: portion). Then the stereotypical meaning 'elevating others' was offered to elucidate the relationship with a strong causal connective 'ttaymun' (because).

In this section, we present our findings concerning the relationship between the stereotypical meanings and contextual meanings with the reasons drawn from our qualitative analysis using group queries in NVivo. Due to restrictions of space and data size, we present findings for three major contextual meanings only, namely, image management, politeness, and building solidarity.

In the analysis, these three contextual meanings were set as axes while all stereotypical meanings and reasons were tested for a relationship with each axis. The analysis results show, however, that not all stereotypical meanings and reasons are relevant for creating contextual meanings. That is, each contextual meaning associates with a different set of stereotypical meanings and reasons. For example, the contextual meaning 'image management' is constructed on the stereotypical meanings 'lowering oneself' and 'elevating others' only. It is a result of strategic deliberation, traditional Korean culture and age (Figure 2). 


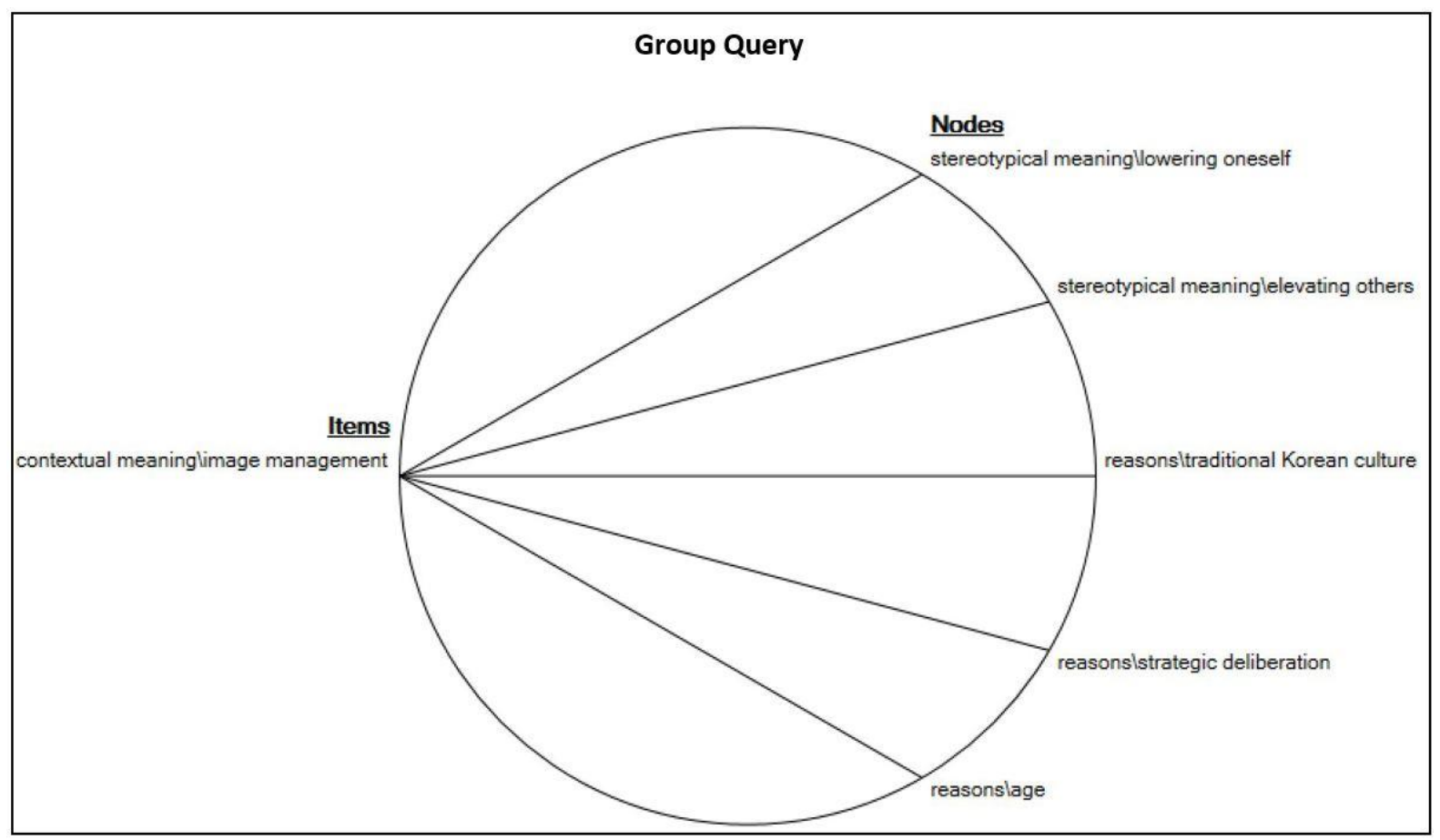

Figure 2. construction of image management

'Age' as a reason in Figure 2 seems to suggest that the contextual meaning 'image management' should relate to the stereotypical meaning '(using to) older people', which is obviously not found. Instead, the finding shows that the 'image' is managed not through using ce to reflect the age difference between Kim Jong Un and his hearer(s), but rather as an expression of Kim Jong Un's awareness of the aging society in South Korea.

\section{Example (2)}

50s_Male_05:...wuli nala-ka cemcem nai-ka manh-un nolyenghwa sahoy-lo ka-ko iss-nun sangthay-eyse casin-i yukcheycek-in nai-na ilen kes-ulo pol-ttay hana-uy kukkataypyo-ey wichihay iss-ciman kayincek-ulo sangtay-lul concunghay-cwu-nun tushan nukkim ttaymun-ey sangtanghi namhan-eyse pihokamcek-in Kim Jong Un wiwencang-ey tayhan kes-cocha-to nwukulettuli-lyeko hayss-ten etten yakkan-uy cenlyakcek swusapep-i anin-ka kulen sayngkakto tun-ta.

'Considering that South Korea is becoming an aging society and considering the fact that Chairman Kim's physical age is young and he is a representative of a country, I think Chairman Kim Jong Un's expression showing a respectful attitude toward his counterpart could be strategic rhetoric to soften his unfavorable image in South Korea.'

In this example, 50s_male_05 placed Kim Jong Un's use of ce against the societal background of South Korea becoming an aging society. Kim Jong Un was able to soften his image by 
contrasting his status as a national leader with the honorific meaning of $c e$ that he personally applied to the aging society. Interestingly, the interviewee used the word sangtay (lit: opponent) to refer to the aging society he described. He seems to consider Kim Jong Un's image from the perspective of an 'opponent' member of the aging society rather than simply being a member of the category 'older people'. This perspective well explains why the stereotypical meaning 'elevating others' (i.e. elevating the opponent) is related to the contextual meaning 'image management', but '(using to) older people' is not.

The second contextual meaning 'politeness' is connected to three stereotypical meanings and four reasons (Figure 3). The stereotypical meanings underpinning 'politeness' are 'lowering oneself', 'elevating others' and 'older people'. Interestingly, the other stereotypical meanings 'nonacquaintance/group audience/people with power' are not associated with 'politeness'. That means, ce might be used in these relationships, but not for communicating politeness in the political context.

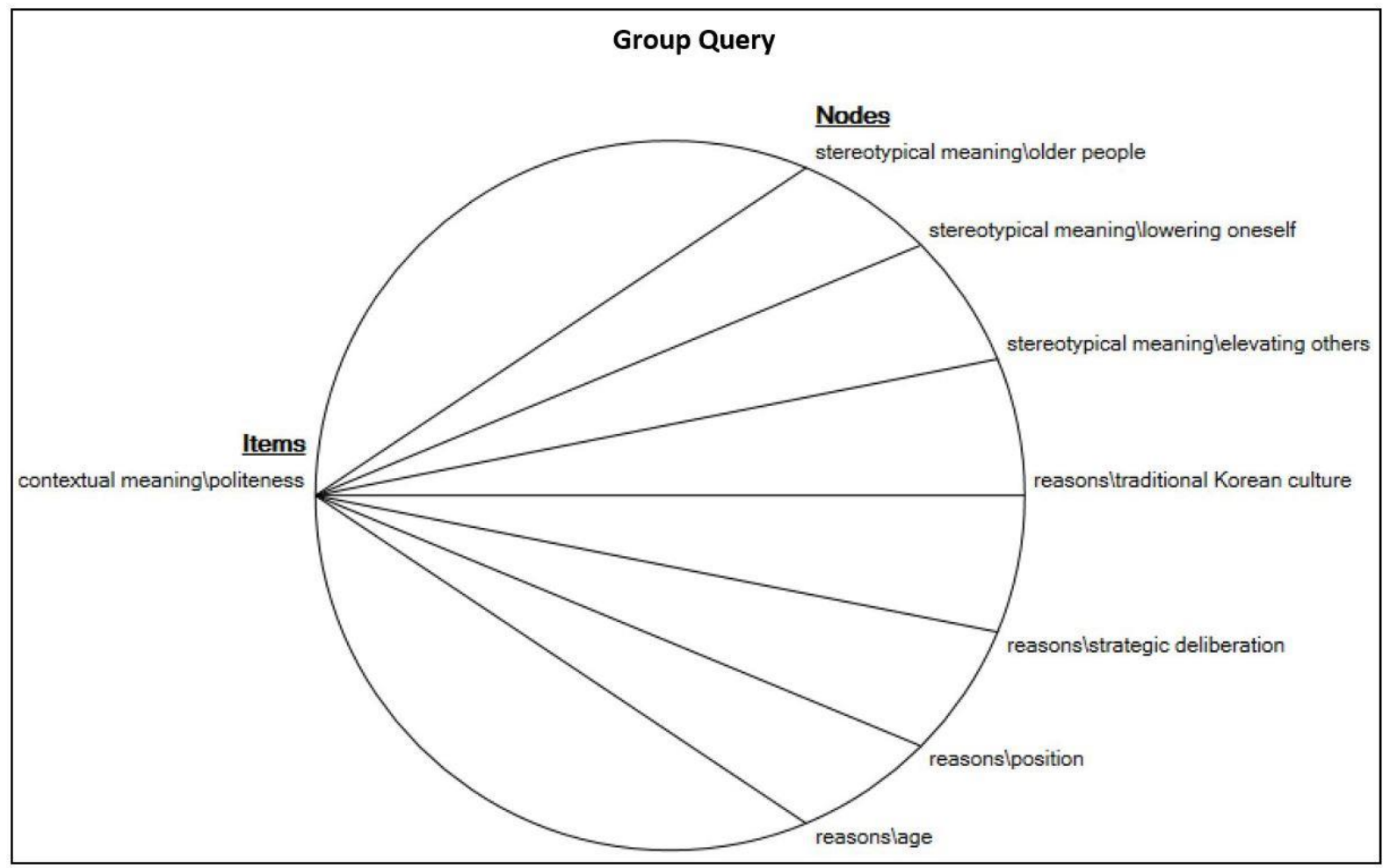

Figure 3. construction of politeness

The interviewees found both contextual and conventional reasons for 'politeness'. The reasons 'traditional Korean culture' and 'age' indicate interviewees' observation of social conventions, while 'position' shows their contextual awareness. The mixture of reasons may 
lie with the remarkable individual variation in understanding whether it is context or convention which is the yardstick for assessing 'politeness'. For example,

Example (3):

40s_male_04: wuli nala-ka tongyang-i-ko, tongpangyeyuycikwuk-in kulen mayklak-eyse poass-ul ttay caki-pota han seytay wi-ey iss-nun Moon Jae In taythonglyeng-eykey kyemyangcek-in phyohyen-ulo hayss-ta, sangtanghi yeyuypalu-key picwu-eci-ess-tako sayngkakhan-ta.

'As an East Asian country, considering that Korea is the Eastern Land of Courtesy, Kim used honorific language to President Moon who is one generation older. Chairman Kim is recognized as courteous.'

30s_male_03: concwung-uy uymi-lo ce-la-nun phyohyen-ul ssu-nun kes kath-ta-nun nukkimul pat-ass-ta. ... kongkayseksang-ey nawa-se phyohyen-ul hay-ya ha-ki ttaymun-ey ama naypwu-eyse-to hal nayyong-ey tayhan kes-tul-to cwunpi-lul hayss-ki ttaymun-ey keki-se phyohyen-uy chai-to enucengto yensup-kwa sanguy-lul han kes kath-ta.

'I got the feeling that ce was used for the meaning of showing respect. As Kim had to announce his statement in a public place, possibly officials from North Korea prepared what he would say. I guess they discussed the difference between the two words and practiced for the statement.'

40s_male_04 in the above example values Korea as "the Eastern Land of Courtesy," which provides the overall social standard for any kind of politeness. He attributes Kim Jong Un's ce, therefore, to defined social conventions. In contrast, 30s_male_03 considers the politeness to have been created as a result of careful preparation and discussion for this public occasion, showing his context-specific judgment.

The third important contextual meaning, 'building solidarity', is associated with two stereotypical meanings: 'lowering oneself' and 'nonacquaintance' (Figure 4). Significantly, we note that 'lowering oneself' helps to build solidarity while 'elevating others' does not. Solidarity built through the use of ce appears with nonacquaintance only, but not with aging people, people with power or the group audience in this political context. 


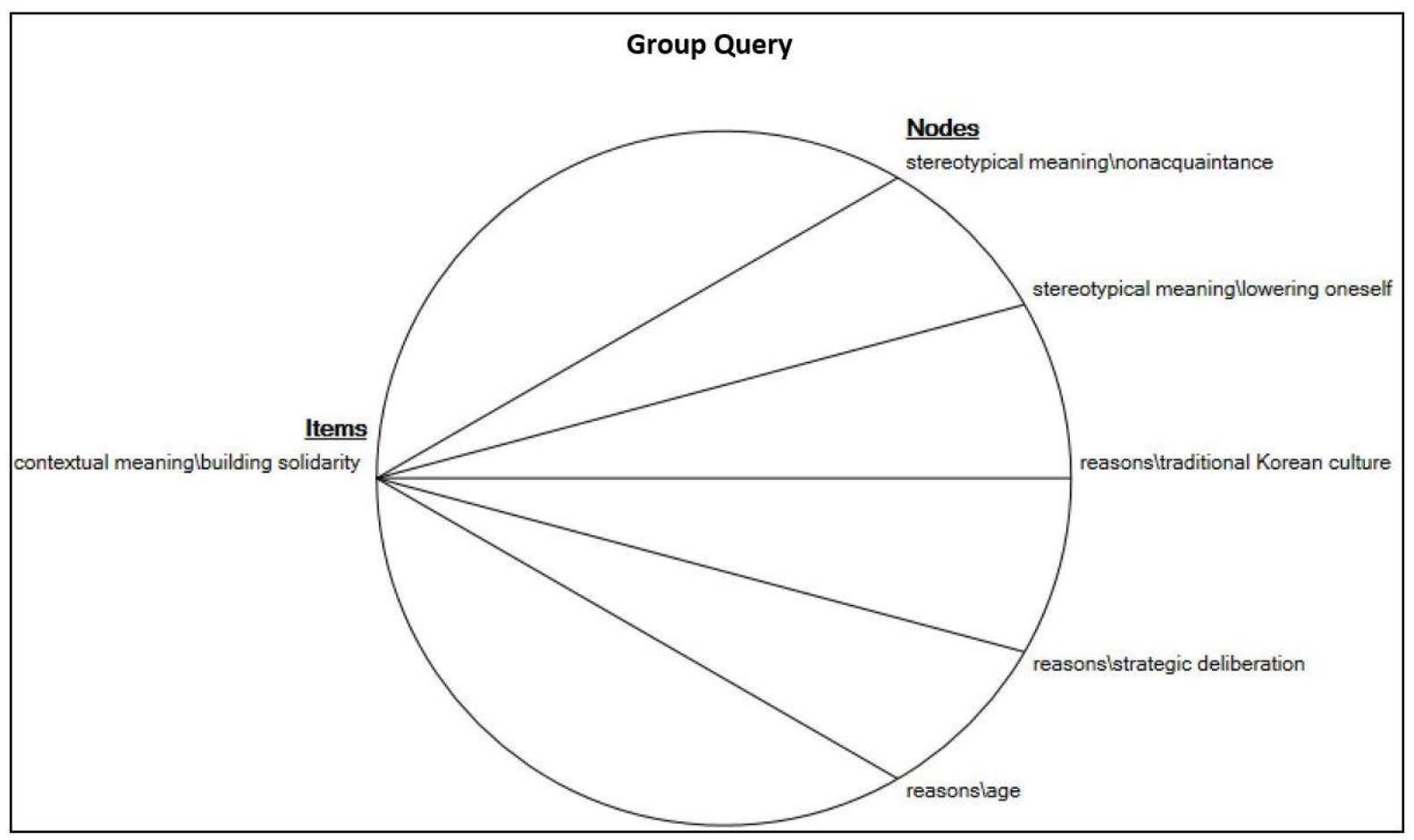

Figure 4. construction of building solidarity

There are three reasons for the solidarity built via ce. However, two of them, 'age' and 'traditional Korean culture', are allocated only by people in the age group 50s, whereas interviewees in their 30s and 40s attribute it only to one reason: 'strategic deliberation'. In other words, different age groups ascribe their meaning interpretations to different reasons.

This difference across age groups may have historical reasons. People in their 50 s, compared to those in their $30 \mathrm{~s}$ and $40 \mathrm{~s}$, are closer to the history of North-South Korean division that occurred between 1945 and 1948 and the Korean War between 1950 and 1953. They are children of the generation that experienced the tremendous transformation from a unified country to two separate nations. People in their 50s may thus be more aware of the same ethnic and linguistic origin that both Koreas have than later generations. Just as 50s_male_04 commented, "I think this is hard to express in English, but Chairman Kim used those expressions because we are of the same culture and language." (kuke-nun ettehkey po-myen cey-ka pol-ttay-nun tongcok-i-lase tongilhan sowimalhay-se munhwa, enekwen nay-eyse ssuki ttaymun-ey [pause] ama ikey yengesik pyonhyen-ulo-nun sangtanghi phyohyen-i himtul kes kath-untey).

Comparing figures 3,4 , and 5 shows that different contextual meanings are related to different stereotypical meanings and resulted from different reasons. Closely examining the varied relationships, however, have shown that some of the stereotypical meanings, (using to) people with power/group audience, do not contribute to communicating any of the tested contextual 
meanings. In the next section, we will discuss the different accessibilities of stereotypical meanings in their relationships with contextual meanings.

\section{Discussion}

The first and fundamental question underlying our findings is the mechanism that contextual meanings are related to stereotypical meanings. More specifically, why different contextual meanings are related to different subsets of stereotypical meanings? In other words, how is a stereotypical meaning selected when people construe certain contextual meanings? In this section, we first consult the Relevance Theory (hereafter RT) from Sperber and Wilson (1995) and Wilson and Sperber (2004) to understand the cognitive mechanism which enables people to connect a stereotypical meaning to a contextual meaning. We then examine this relevancetheoretical approach in the current findings and reify the cognitive mechanism with people's contextual awareness and language ideologies.

The RT proposes two principles, the Cognitive Principle and the Communicative Principle, to understand people's meaning communication. According to the Communicative Principle, ce, as the ostensive stimulus picked up by South Korean audience, is presumed to provide the optimal relevance to the messages that Kim Jong Un intended to communicate (i.e. the Presumption of optimal relevance, 2004:612). The audience's cognition is geared to maximize the relevance (the Cognitive Principle, 2004:610), through activating available cognitive resources, such as the stereotypical meaning stored in memory. The activation is, however, a selective process via the audience's tests of different interpretive hypotheses in multi-layered contexts, or in Sperber and Wilson's (1995:146) term, extensions of context. The contexts include not only the occurrent speech, but also the Panmunjom Declaration co-signed before the speech, the summit as a larger background, and histories between the two countries. The audience's contextual awareness and language ideologies of ce mediate their selection of stereotypical meanings when construing a contextual meaning.

This argument is supported by previous studies including Silverstein (2003) which considers the effectiveness of contextual meanings to be built through different engagements of ideologies at the metapragmatic level, pronominal studies that we reviewed in Section 2, and recent politeness studies undertaken from a relevance-theoretic approach. Chen (2014), for example, describes how different schematic knowledge can be unequally activated to convey the contextual meaning 'politeness' through a variety of associations with politeness strategies, contents, and manners in context. Below, we discuss the specific ways that context and language ideologies mediate the accessibility of different stereotypical meanings in creating contextual meanings. 
Starting from the stereotypical meaning '(using to) people with power', which is not involved in creating any of the contextual meanings, we observe that this is consistent with the context in which Kim Jong Un, as a national leader, is already one of the most powerful representatives at the summit. Besides, the summit was held on the basis of equality between two nations. Therefore, $c e$ is unequivocally not used to assign Kim Jong Un himself to a less-powerful role or to address any power asymmetry based on that contextual consideration. As a result of this mismatch between the language ideology and contextual need, this stereotypical meaning has not or very little efficiency in generating any contextual effect for Kim Jong Un's use of ce.

Another stereotypical meaning '(using to) group audience' is also not associated to any of the tested contextual meanings. The ideology of 'group audience' presupposes the speaker to be one of the group members, who should present him/herself in structured scenes with a level of linguistic formality (see Section 4.2.1). This ideology was manifested by Moon Jae In in his public speeches into humility and loyalty to his national people on the domestic stage (Kim, 2018). However, compare to the intranational stage, the international stage entails different consideration of these manifestations. That is, although the public occasion is a typical context where formality applies, both Moon and Kim appeared highly conscious of not placing themselves in the 'same' group as the audience from the other's country and consequently creating the 'wrong' message of humility and loyalty. Moon Jae In, for example, changed to use na completely in his speech in contrast to his use of ce on the domestic stage.

Kim Jong Un, on the other hand, used ce but only when he himself and Moon Jae In copresented as the subject of the sentence (i.e. "President Moon Jae In and I"). This indicates the contextual meanings of $c e$, or at least some of them, are only evoked (intentionally or not) with regard to specific agent(s) in the discourse. The properties and characteristics of the agent are also relevant for the construction of contextual meanings. For example, Moon Jae In was characterized by interviewees as an older person, the ideologically recognized social superiors, towards whom certain treatment may promote or damage one's own reputation (see Section 4.2.1). Through exploiting this ideology by paying deference (i.e. lowering oneself and elevating others) to an age-superior, Kim Jong Un created 'politeness'. In other words, his linguistic behavior (i.e. using ce) was evaluated by his audience as polite in this context.

Another contextual meaning 'image management' was also realized through lowering himself and elevating others, but not related to 'older people' and any other type of agents. 'Lowering oneself' and 'elevating others' are informed by the ideology of deference in Korean. Kim Jong Un's deference, however, would hardly be conceivable by the South Korean audience, given the long-standing antagonistic relationship between North and South Korea. As found in Section 5, South Korean interviewees metapragmatically categorized themselves as an 
'opponent'. However, it is precisely this self-declared 'opponent' for whom Kim Jong Un was changing his image, rather than a general population of 'older people/nonacquaintance/group audience/people with power'. The way that our participants interpret the meaning also coincide with meaning-comprehension processes proposed by the RT (2004:615). Following the theoritical approach, the contextual assumption that Kim Jong Un changes his image through showing deference to older people (or nonacquaintance/group audience/people with power) needs to be tested against previous knowledge that he rarely shows deference to these people. The test is easily falsified for lack of evidence or by a previous counter example. In contrast, the assumption that Kim Jong Un changes his image for opponents can be testified in the current context with one of the main goals set in the Panmunjom Declaration being an end to the confrontational relationship (Section 2).

The last contextual meaning 'solidarity' was sought with nonacquaintance by lowering oneself. Identifying their relationship as distant (i.e. nonacquaintance), Kim Jong Un and our interviewees seem to have drawn a line between in-group and out-group. This in- and outgroup distinction is also corroborated by the above discussion about Kim Jong Un being cautious to not position himself in the same group as the South Korean audience. It well reflects the contextual specificity of the summit, pursuit of which is solidarity across two separate nations. To close the distance with group outsiders from another nation then, 'lowering oneself' is more efficient than 'elevating others', because sacrifice of one's own interests (i.e. self-sacrifice) rather than satisfying others' results in strong identification with the group (Bierhoff and Küpper, 1999).

In summary, language users assess in the multi-layered context whether and how to exploit their language ideologies in the process of communicating contextual meanings. The exploitation reflects their investment into meaning constructions, resulting in the varied relationships between stereotypical meanings and contextual meanings. The relevancemaking mechanism following the RT principles may function unconsciously in many discourses. However, as much as is retrievable in people's explicit metapragmatic accounts, it can be manipulated strategically to create intended contextual meanings, just as those that have been communicated via ce in the summit. In this instance, the variety of relationships between stereotypical meanings and contextual meanings are the very indications of how the speaker and his audience cooperatively exploit language ideologies, assess what a context entails and maximize the cognitive relevance.

\section{Conclusion}


In this study, we have explored the relationship between the stereotypical meanings and contextual meanings of $c e$ through Korean native speakers' metapragmatic discourse. Our examination of their relationship revealed that: (1) people's interpretations of contextual meanings are constructed upon their knowledge of stereotypical meanings, following the RT principles; (2) different contextual meanings of an honorific are related to different ranges of its stereotypical meanings; and, most importantly, (3) the varied relationships between stereotypical and contextual meanings can be examined through language ideologies exploited by language users in different layers of context.

The nexus found between metapragmatics, language ideologies and pragmatics potentially benefits multiple areas of studies such as politeness, ethnolinguistics and sociolinguistics. In addition to these potential contributions, we would like to highlight its importance in studies of second language acquisition. Although this study carried its investigation out with native speakers, the interlinks it found between people's metapragmatic awareness, relevancemaking process, language ideologies, pragmatic interpretations and context correspond nicely with recent research interests in the transdisciplinary nature of second language acquisition (Douglas Fir Group, 2016; Duff, 2019). These studies examine second language learning in relation to macro-meso-micro levels of factors, in our instance, from language ideologies at the macro-level (i.e. belief system) to interlocutors' cognitive investment in a conversation at the micro-level (e.g. metapragmatic awareness). The relationship between stereotypical meanings and contextual meanings revealed by the current study, therefore, provides a reference to the variable ways that these factors engage in people's pragmatic knowledge construction and pragmatic competence. We encourage the use of these findings to address the gap between language learners' normative knowledge and their actual practice of using honorifics. By grasping how they become capable of interpreting contextual meanings from learning stereotypical meanings, we expect future studies to deepen our understanding of the mechanisms underlying second language learners' development of pragmatic competence.

\section{References}

Agha, Asif. 1998. Stereotypes and registers of honorific language. Language in Society 27(2). 151-193. https://doi.org/10.1017/S0047404500019849.

Agha, Asif. 2004. Registers of language. In. Duranti, Alessandro. (ed.). A Companion to Linguistic Anthropology. Blackwell. 23-45.

Bierhoff, Hans. W., Küpper, Beate. 1999. Social Psychology of Solidarity, in: Bayertz, Kurt. (Ed.), Solidarity, Philosophical Studies in Contemporary Culture. Springer Netherlands, Dordrecht, pp. 133156. https://doi.org/10.1007/978-94-015-9245-1 7

Brown, Lucien. 2008. "Normative" and "strategic" honorifics use in interactions involving speakers of Korean as a second language. Oriental Archive. 76. 269-297. 
Brown, Lucien. 2010. Korean honorifics and 'revealed', 'ignored' and 'suppressed' aspects of Korean culture and politeness. In.Bargiela-Chiappini, Francesca and Dániel Z. Kádár. (eds.). Politeness across cultures. Palgrave Macmillan, London. 106-127.

Brown, Lucien. 2013. "Mind your own esteemed business": Sarcastic honorifics use and impoliteness in Korean TV dramas. Journal of Politeness Research 9(2). 159-186. https://doi.org/10.1515/pr-2013$\underline{0008 .}$.

Brown, Lucien. 2015. Revisiting "polite" -yo and "deferential" -supnita speech style shifting in Korean from the viewpoint of indexicality. Journal of Pragmatics $79.43-59$. https://doi.org/10.1016/i.pragma.2015.01.009.

Brown, Roger. and Albert, Gilman. 1960. The Pronouns of Power and Solidarity. In: Sebeok, Thomas. A. (ed.), Style in Language, 253-276. Cambridge, Mass: MIT Press.

Chang, Suk-Jin. 1996. Korean. Amsterdam, NETHERLANDS: John Benjamins Publishing Company.

Chen, Xinren. 2014. Politeness processing as situated social cognition: A RT-theoretic account. Journal of Pragmatics 71. 117-131. https://doi.org/10.1016/j.pragma.2014.07.010.

Cook, Haruko Minegishi. 2011. Are honorifics polite? Uses of referent honorifics in a Japanese committee meeting. Journal of Pragmatics (Negotiating Linguistic Politeness in Japanese Interaction: A Critical Examination of Honorifics) 43(15). 3655-3672. https://doi.org/10.1016/j.pragma.2011.08.008.

Culpeper, Jonathan, Derek Bousfield \& Anne Wichmann. 2003. Impoliteness revisited: with special reference to dynamic and prosodic aspects. Journal of Pragmatics 35(10). 1545-1579. https://doi.org/10.1016/S0378-2166(02)00118-2.

Douglas Fir Group. 2016. A Transdisciplinary Framework for SLA in a Multilingual World. The Modern Language Journal 100(S1). 19-47. https://doi.org/10.1111/modl.12301.

Duff, Patricia A. 2019. Social Dimensions and Processes in Second Language Acquisition: Multilingual Socialization in Transnational Contexts. The Modern Language Journal 103(S1). 6-22. https://doi.org/10.1111/modl.12534.

Eelen, Gino, 2001. A Critique of Politeness Theories. St John's Publishers, Manchester.

Fetzer, Anita \& Peter Bull. 2008. "Well, I answer it by simply inviting you to look at the evidence": The strategic use of pronouns in political interviews. Text. John Benjamins Publishing Company. https://doi.org/info:doi/10.1075/ilp.7.2.05fet.

House, Juliane, 1989. Politeness in English and German: the functions of please and Bitte. In: BlumKulka, S., House, J., Kasper, G. (Eds.), Cross-Cultural Pragmatics: Requests and Apologies. Ablex, Norwood, NJ, pp. 96-122.

House, Juliane \& Dániel Z. Kádár. 2020. T/V pronouns in global communication practices: The case of IKEA catalogues across linguacultures. Journal of Pragmatics $161.1-15$. https://doi.org/10.1016/i.pragma.2020.03.001.

Hwang, Juck-Ryoon. 1990. 'Deference' versus 'politeness' in Korean speech. International Journal of the Sociology of Language, 41-56. https://doi.org/10.1515/ijsl.1990.82.41

Kim, Jae-Hee. 2018. Taythonglyeng yenselmuney nathanan sahoyenehakcek uymi yenku [On sociolinguistic meaning in presidential speeches: through the lens of Fairclough's critical discourse analysis]. Theyksuthu enehak [Textlinguistics]. 44. 1-33.

Kim, Kyoungho, n.d. "nanun" taysin "cenun"...Kim Jong Unuy kyemson hwapep·enhayng. ['nanun replaced by cenun... the humble way of Kim Joung Un speaking'] MBC NEWS. http://imnews.imbc.com/replay/2018/nwdesk/article/4591186 22663.html (5 June, 2019). 
Kroskrity, Paul V. 2010. Language ideologies - evolving perspectives. In Jaspers, Jürgen, Jan-Ola Östman \& Jef Verschueren. (eds.). Society and Language Use. Amsterdam, Netherlands, The: John Benjamins Publishing Company. 192-211.

Kuo, Sai-Hua. 2002. From solidarity to antagonism: The uses of the second-person singular pronoun in Chinese political discourse. Text - Interdisciplinary Journal for the Study of Discourse 22(1). https://doi.org/10.1515/text.2002.004.

Lee, Jungbok. 1999. Kuke kyengepepuy cenlyacek yongpepey tayhaye ['On the strategic usage of Korean honorifics']. Ehakyenku [Language Research]. 35/1. 91-122.

Mackie, Diane M., Hamilton, David. L., Susskind, Joshua, Rosselli, Francine. 1996. Social psychological foundations of stereotype formation. In. Macrae, Stangor, and Hewstone. (eds). Stereotypes and Stereotyping, The Guilford Press, New York. 41-78

Maitland, Karen \& John Wilson. 1987. Pronominal selection and ideological conflict. Journal of Pragmatics 11(4). 495-512. https://doi.org/10.1016/0378-2166(87)90092-0.

Ministry of Foreign Affairs, Republic of Korea. Panmunjom Declaration for Peace, Prosperity and Unification of the Korean Peninsula (2018.4.27)

http://www.mofa.go.kr/eng/brd/m 5478/view.do?seq=319130\&srchFr=\&srchTo=\&srchWord=\&srchTp $=\&$ multi itm seq=0\&itm seq $1=0 \& \mathrm{itm}$ seq $2=0$ \&company $\mathrm{cd}=\&$ company $\mathrm{nm}=\&$ page $=1 \&$ title $\mathrm{Nm}=$

(11 November, 2019).

Miyazaki, Ayumi. 2004. Japanese junior high school girls' and boys' first-person pronoun use and their social world. In Okamoto, Shigeko \& Janet S. Shibamoto Smith. (eds.). Japanese Language, Gender, and Ideology: Cultural Models and Real People. Oxford, United States: Oxford University Press, 256274.

Morford, Janet. 1997. Social Indexicality in French Pronominal Address. Journal of Linguistic Anthropology 7(1). 3-37. https://doi.org/10.1525/jlin.1997.7.1.3.

Ogawa, Naoko, and Janet, Shibamoto-Smith. 1997. The gendering of the gay male sex class: A preliminary case study based on rasen no sobyoo. In Anna Livia and Kira Hall (eds.), Queerly phrased: Language, gender, and sexuality. New York: Oxford University Press, pp. 402-415.

Okamoto, Shigeko. 1997. Social context, linguistic ideology, and indexical expressions in Japanese. Journal of Pragmatics (Japanese Pragmatics) 28(6). 795-817. https://doi.org/10.1016/S03782166(97)81491-9.

Okamoto, Shigeko. 2011. The use and interpretation of addressee honorifics and plain forms in Japanese: Diversity, multiplicity, and ambiguity. Journal of Pragmatics (Negotiating Linguistic Politeness in Japanese Interaction: A Critical Examination of Honorifics) 43(15). 3673-3688. https://doi.org/10.1016/i.pragma.2011.06.012.

Pizziconi, Barbara. 2011, Honorifics: The cultural specificity of a universal mechanism in Japanese. In Kádár, Dániel Z., and Sara Mills. (eds). Politeness in East Asia. Cambridge University Press. 45-70.

Proctor, Katarzyna \& Lily I-Wen Su. 2011. The 1st person plural in political discourse-American politicians in interviews and in a debate. Journal of Pragmatics 43(13). 3251-3266. https://doi.org/10.1016/i.pragma.2011.06.010.

Silverstein, Michael. 1979. Language Structure and Linguistic Ideology. In Clyne, Paul, William. Hanks \& Carol, Hofbauer (eds.) The Elements: Chicago Linguistics Society. 193-248.

Silverstein, Michael. 1993. Metapragmatic discourse and metapragmatic function. In. Lucy, John A. (ed.). Reflexive Language: Reported Speech and Metapragmatics. Cambridge University Press. 33-58.

Silverstein, Michael. 2003. Indexical order and the dialectics of sociolinguistic life. Language \& Communication (Words and Beyond: Linguistic and Semiotic Studies of Sociocultural Order) 23(3). 193-229. https://doi.org/10.1016/S0271-5309(03)00013-2. 
Simpson, Rita C. 1997. Metapragmatic Discourse and the Ideology of Impolite Pronouns in Thai. Journal of Linguistic Anthropology 7(1). 38-62. https://doi.org/10.1525/jlin.1997.7.1.38.

Sperber, Dan, and Wilson, Deirdre. 1995. Relevance: communication and cognition. 2nd ed. Blackwell. Thibaut, John.W., Kelley, Harold. H. 1959. The social psychology of groups. Wiley, New York.

Verschueren, Jef. 2000. Notes on the role of metapragmatic awareness in language use. Pragmatics 10(4). 439-456. https://doi.org/10.1075/prag.10.4.02ver.

Wilson, Deirdre, and Sperber, Dan. 2004. Relevance Theory. In Horn, Laurence, and Gergory Ward (eds). Handbook of Pragmatics. Hoboken, United Kingdom: John Wiley \& Sons, Incorporated. 607-631.

Yeon, Jaehoon, and Brown, Lucien. 2011. Korean: a comprehensive grammar. Routledge, Oxon [England].

Yoon, Kyung-Joo. 2004. Not just words: Korean social models and the use of honorifics. Intercultural Pragmatics 1(2). 189-210. https://doi.org/10.1515/iprg.2004.1.2.189.

Zheni, Thouraya. 2020. Person Deixis as Biased Political Pronouns in George W. Bush's Speeches on Iraqi War II. International Journal of Language and Literary Studies 2(1). 155-171. https://doi.org/10.36892/ijlls.v2i1.112. 